\title{
A economia do património e o turismo
} António Queirós ${ }^{1}$

\begin{abstract}
Resumo
O turismo não é apenas e exclusivamente uma atividade económica, mas jamais devemos subestimar esta sua dimensão primordial, e, porventura, a sua crescente importância económica é indissociável de algumas das mais profundas mudanças políticas e sociológicas que marcaram o século $X X$ : 0 crescimento da classe média instruída e da sua mobilidade, facilitada pela formidável revolução técnico-científica e a mudança do seu conceito de "gosto"; a institucionalização e ampliação dos direitos democráticos dos cidadãos; a contenção da guerra; mas também de uma ainda mais radical mudança antropológica, o reposicionamento do Ser Humano no quadro da Filosofia da Natureza e do Ambiente e das suas Éticas Ambientais, quer a atividade turística disso se aperceba ou não, cega pela aparência das formas económicas tradicionais e pela expansão e sucesso ininterrupto desta atividade nos últimos cinquenta anos, marcados pelo empirismo e a absolutização do turismo como atividade económica de serviços.

A economia do turismo, na sua relação com o património e a constituição e reprodução do capital turístico apresentam algumas singularidades que pretendemos investigar: como se produz a mercadoria turística e reproduz o capital turístico, como se processa a formação do seu valor, preço e concorrência, qual a natureza e a essência económica da atividade turística, questionando simultaneamente os conceitos tradicionais de comum sector de serviços ou indústria do turismo, tourism industry.
\end{abstract}

Palavras-chave: Gosto. Turismo Cultural. Externalidades.

${ }^{1}$ Doutor em Filosofia das Ciências, Professor, Investigador, na área da economia e gestão do turismo cultural e de natureza, Universidades de Aveiro (Departamento de Economia, De Gestão e Engenharia Industrial) adsqueiros@gmail.com 


\begin{abstract}
Tourism has been studied as an economic activity, from their products and businesses activities. But why are travelling peoples and for what? What's happen in the tourism world under the iron hand of the modern market, analysed from the both sides, demand and offer, with the emergence of the society of knowledge and information, with their new middle class growing with more education and culture, a young people predisposed to the e-learning and a increasing segment of tourists who anticipate the middle-aged and retire?

A new conceptual research framework emerges and a new tourism paradigm: Environmental Tourism (Cultural tourism and tourism of nature).

This paper wants to discuss the connection between heritage and tourism economy. Researching how is create and reproduced the capital of tourism and recognising the cultural values and products penetration in the tourism activity, in the framework of the changing taste (preferences) and ethical values of middle class.
\end{abstract}

Keywords: Taste. Cultural tourism. Externalities

\title{
ENQUADRAMENTO METODOLÓGICO E ENUNCIADO DOS TEMAS
}

Adotamos aqui o quadro conceptual proposto no ensaio "Turismo Cultural e Economia do Património":

"Toda a teoria científica tem como suporte um conjunto de axiomas. A metodologia do trabalho científico consiste no desenvolvimento desses axiomas para deles retirar consequências "físicas", isto é, no caso do turismo, para analisar a sua fenomenologia. Tal significa, no estudo da evolução prática da atividade turística, explicar e prever os seus resultados, através da prática da observação dos seus fenómenos ou da experimentação dos seus processos. Para que a concetualização formal do turismo se conforme com a construção de uma hermenêutica científica, ela deve ser capaz de 
estabelecer uma relação dialógica entre a observação e os conceitos matemáticos (em sentido amplo) e esforçar-se por identificar os fenómenos que correspondem aos conceitos abstratos elaborados pela investigação na área do turismo. " (Queirós, 2014: 108)

É óbvio que neste texto a dimensão da pesquisa se deve confinar quer à natureza quer aos limites de um artigo. Pelo que o autor optou por circunscrever o número de axiomas e dirigir o desenvolvimento teórico do artigo em duas direções, para a comunidade académica, mas também para os decisores políticos e económicos, procurando demonstrar a estes que estamos em presença de questões teóricas de vital importância para o bom andamento da sua governação e dos seus negócios.

São assim dois axiomas a problematizar:

_ Estamos face a face com o desafio de "repensar" as relações entre património e turismo, particularmente na sua dimensão económica?

_ Existem atualmente no mercado turístico "estranhos fenómenos", não explicáveis pelas leis tradicionais do mercado, que indiciem a configuração de uma economia específica do turismo, no quadro da emergência de um novo paradigma, onde o património é fator decisivo da mudança!? Iniciemos a reflexão.

\section{A economia do património e o turismo. Investing in success}

O tema tem sido objeto de estudo nos países mais desenvolvidos em matéria de turismo e valorização do património e os dados adiante citados referem-se ao Reino Unido, conforme recensão realizada pelo engenheiro Vasco Costa, o último dos diretores da Direção Geral do Património. A importância do património para o 
sucesso da nova economia do turismo está aqui bem documentada. Tomamos como referência a publicação da obra Investing in success. Heritage and UK tourism economy (2010), que cita inicialmente o estudo encomendado à Oxford Economics, Economic impact of the UK heritage tourism economy, em 1999.

"The popularity of heritage is well understood, and we have long had the numbers that confirm this. Some $53 \%$ of the population makes a trip to experience the atmosphere of a historic town or city at least once a year, and $42 \%$ visit a museum or gallery. The total number of visits to museums and galleries has been estimated at over 40 million a year, whilst 1.2 billion visits are made to the countryside. Over 10 million visits are made to historic parks, more than 38 million to historic houses, cathedrals and castles, and more than 250 million to Britain's inland canals and waterways. Historic houses in private ownership play a crucial part in supporting this essential national resource, welcoming 14 million visitors each year...

The economic impact of the heritage sector has been underestimated by politicians, economists and business leaders trying to get the British economy moving again. Part of the reason is that the data to make our case hasn't been available...

This report is the first to provide those missing numbers. It demonstrates that the heritage-based tourism economy is bigger than other studies have previously suggested, contributing an estimated 
E20.6billion to the gross domestic product and that investing in our heritage makes sense now more than ever."

Retiremos dos artigos da obra citada alguns quadros e citações, para os comentar:

O seu contributo para o rendimento económico é superior aos principais ramos industriais e, como sector charneira da economia, apresenta múltiplos impactos na criação de riqueza e de emprego. Ao património construído soma-se um peso equivalente do denominando património natural, que é de facto a sobreposição dos valores da paisagem humanizada com os valores da denominada vida selvagem. Esta realidade explica os comentários seguintes, que a sublinham e ilustram. O primeiro, de Dame Jenny Abramsky, Chair of the Heritage Lottery Fund:

"Investing in success:

With the tourism economy estimated to grow even more over the next 10 years, investing in our heritage makes sense now more than ever. ...Every f1million of HLF funding leads to an increase in tourism revenues for regional economies of £4.2million over 10 years." (Abramsky, 2010: 2,20) 
Fig 1 e 2. Quadros comparados do Valor Acrescentado pelo património à renda do turismo e a sua contribuição para o PIB.

\begin{tabular}{|c|c|c|}
\hline $\begin{array}{l}\text { Expenditure (per year) } \\
\text { by type of visit }\end{array}$ & $\begin{array}{r}\text { Exduding } \\
\text { natural heritage }\end{array}$ & $\begin{array}{r}\text { Including } \\
\text { natural heritage }\end{array}$ \\
\hline International tourism & £2.6bn & \&4.9bn \\
\hline Domestic overnight stays & sિ.5bn & sl.1bn \\
\hline Domestic day trips & \&4.2bn & 56. $4 \mathrm{bn}$ \\
\hline Total expenditure & \$7.3bn & \$12.4bn \\
\hline \multicolumn{3}{|l|}{ GDP contribution (per year) } \\
\hline Total 'direct' GDP contribution & f4.3bn & \&7.4bn \\
\hline GDP contribution ind. multiplier impacts & \&11.9bn & £20.6bn \\
\hline \multicolumn{3}{|l|}{ Employment } \\
\hline Employment (jobs) & 113,000 & 195,000 \\
\hline Employment (jobs) ind. mult iplier impacts & 270,000 & 466,000 \\
\hline
\end{tabular}

\begin{tabular}{lr}
$\begin{array}{l}\text { Fg 2: Examples of sector } \\
\text { contributions fo UK GDP12 }\end{array}$ & $\begin{array}{r}\text { GDP contribution } \\
\text { (per year) }\end{array}$ \\
\hline Industry & $£ 10.0 \mathrm{bn}$ \\
\hline Publishing & $\$ 9.6 \mathrm{bn}$ \\
\hline Agriculture & $\$ 7.4 \mathrm{bn}$ \\
\hline Heritage visitor economy & $£ 6.5 \mathrm{bn}$ \\
\hline Electricity generation & $£ 5.8 \mathrm{bn}$ \\
\hline Advertising & $\$ 5.5 \mathrm{bn}$ \\
\hline Motor-vehicle manufacturing & $\$ 3.3 \mathrm{bn}$ \\
\hline Film
\end{tabular}

Fonte: Heritage Lottery Fund. (Page 9)

Trata-se de uma taxa de rentabilidade económica absolutamente notável, catalisadora do merchandising tradicional e cultural. $\mathrm{O}$ segundo, de Sandie Dawe MBE, Chief Executive of VisitBritain:

"Valuing heritage tourism:

Our heritage economy is vibrant, and a crucially important part not just of the 1114 billion visitor economy, but of our local, regional and national economies as well. 
Our heritage attractions are the very product of travel and tourism; built according to international influences, filled with souvenirs and artefacts, suffused with stories of characters all drawn from international travel." (2010, Dawe: 3.4)

Fig. 3 e 4 . O património como fator de motivação do turismo internacional e do turismo nacional.

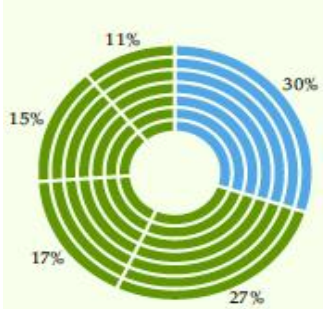

Fig 3: Main molivations for internation d frips ${ }^{13}$

\begin{tabular}{|c|c|}
\hline Heritage & $30 \%$ \\
\hline Business & $27 \%$ \\
\hline Visiting friends and family & $17 \%$ \\
\hline $\begin{array}{l}\text { Non-heritage holiday motivations } \\
\text { (ind. contemporary arts and culture, } \\
\text { sport, shopping) }\end{array}$ & $15 \%$ \\
\hline Other & $11 \%$ \\
\hline
\end{tabular}

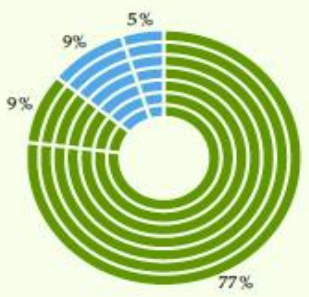

Fig 4: Main motivations

for domestic-fourism day frips ${ }^{14}$

Other (incl. shopping trip, cinema, meal out, night out at bar or pub)

Trip to visitor attraction

- non-heritage

Trip to visitor attraction

- heritage

Visit to park/countryside

- natural heritage

$5 \%$

Fonte: Heritage Lottery Fund, Page11. 
Um sector que apresenta uma grande resiliência à própria crise económica. Como sublinha Simon Thurley, Chief Executive of English Heritage

"Heritage tourism and the post-recession Economy:

We believe that heritage tourism can become an increasingly important sector of them UK economy as we come out of recession and move towards recovery." (Thurley, 2010:13)

Roy Clare CBE, Chief Executive of the Museums, Libraries and Archives Council, destaca o papel dos museus como estruturas orgânicas do Turismo Cultural e da sua economia:

"Museums, flagship libraries and archives play a central role in supporting the visitor economy... All museums, including those in local-authority ownership, need support to make stronger contributions to tourism economies." (Clare,210:15,16)

A paisagem cultural e os seus valores associados à vida selvagem como novos produtos do turismo de natureza e do turismo em espaço rural, segundo lan Jardine, Chief Executive of Scottish Natural Heritage:

"The role of natural heritage in driving tourism:

The country's stunning landscapes and wildlife attract tourists from near and far, and are consistently cited as the most important factor in drawing visitors to Scotland.... The country's stunning landscapes and wildlife attract tourists from near and far, and are consistently cited as the most important factor in drawing visitors to Scotland. 
There is no single report that quantifies the economic benefits of nature-based tourism, although various different studies give an indication of the importance of the sector. For example: whale-watching in Scotland is estimated to bring in £10.7million a year;

- anglers spend an estimated f113million a year on fishing in Scotland's famous rivers including the Spey, Dee, Tay and Tweed; - wild geese attract birdwatchers, wildfowlers and tourists, who contribute f3.5million a year; - sea eagles bring f1.69million a year to the Mull economy; ospreys have become a popular tourist attraction, bringing in 125,000 visitors who spend an additional $£ 2.2$ million every year; - watching seabirds at the Scottish Seabird Centre, North Berwick, brings over f1million a year into the local economy; - wild deer are a great attraction for tourists, with deer-management generating 1105 million a year; • outdoor activities such as walking and cycling are growing in popularity. Over 330 million visits were made to Scotland's outdoors for recreation purposes in 2007. "(Jardine, 2010:23)

Para concluir com Stephen Johnson, Chair of the Broads Authority, sobre a importância dos parques naturais como estruturas orgânicas do Turismo de Natureza:

"Enhancing the visitor experience through the heritage:

Almost a quarter of all tourists walk as their main activity or as part of a trip enhancing the visitor 
experience through heritage. The Broads' value to residents and visitors is well researched and established. In 2008, the wetland attracted around 11 million visits, which generated a total spend in the area of 1413 million." (Johnson, 2010:25)

\section{UMA NOVA E ESPECÍFICA ECONOMIA DO TURISMO}

A nova economia do turismo pode ser percecionada através de estudos monográficos sobre o valor e impacto económico do património. O "estudo de caso" da Parques de Sintra, Monte da Lua (PSML), do Museu do Relógio, de Serpa e do Palácio de Versalhes, conduziu-nos a uma comum matriz de gestão: São entidades gestoras do património, com uma situação económica e financeira sustentável, que cobre praticamente a totalidade do seu orçamento com os resultados da exploração e até criam superavit, que aqui apenas anotaremos, limitados que estamos pela dimensão de um artigo.

A que associamos, nesta introdução à nova economia do turismo, três outros exemplos merecedores de um artigo autónomo; aqui os mencionamos sumariamente e como referência para o leitor empenhado, que deseje ir mais longe na sua pesquiza neste tema:

A realização pela Faculdade de Economia da Universidade do Porto do estudo do "Impacto Económico da Fundação de Serralves. Relatório Final"), coordenado pelo professor José Costa, o qual conclui (em 2010), que Serralves, apesar de longe do autofinanciamento alcançado pelas três entidades anteriores, pois na trajetória de 2000 a 2010 os Subsídios do Estado e de O.E. Públicos elevaram-se de 52,25\% a 65,44\%, (5,08 milhões de 
euros) gera em contrapartida um impacto global sobre o PIB de cerca de 40,56 milhões de euros.

A tese de doutoramento de José Maria da Cunha Rego Lobo de Carvalho, "Conservação do Património. Políticas de sustentabilidade económica (orientação do Professor Catedrático José Lamas). Lisboa: IST, 2009", na linha de investigação orientada para a zona monumental de Belém, em Lisboa, que realizou em 2003 onde se evidenciam os efeitos multiplicadores das visitas turísticas sobre a economia local.

E, finalmente, a investigação que parte do Museu Monográfico de Conimbriga e do seu Centro de Formação, o Cefop.Conimbriga: O "estudo de caso" de Conimbriga, como microcosmo do turismo nacional, fundamenta-se na sua capacidade de atração nacional e internacional, na natureza dos seus visitantes, onde o predomínio dos turistas sobre os excursionistas é significativo, na segmentação dos dados disponíveis sobre os seus públicos_integrando jovens escolares e outros jovens, turistas de outros países (cerca de 30\%) e turistas nacionais de todo o país, em equilíbrio de género, de todas as classes sociais e etárias, e na existência de um inquérito sistemático (ao longo dos últimos vinte anos) aos seus públicos que engloba, no mínimo,12 itens: Idade. Forma de organização da viagem. Preparação da Visita com recurso à Internet. Outras atividades durante o mesmo dia e noite. Visitas anteriores. Composição do grupo/Número de pessoas. Gastos pessoais em Euros €. Tempo da visita/ Horas. Grau de satisfação. Alojamento/Lugar onde vai dormir. País de Residência. Transporte de chegada ao país. Os dados objetivos da investigação, com séries anuais de inquéritos da ordem de um a dois ou três milhares, repartidos pelas quatro estações, as quais representam agregados diferentes de público, demonstram que o turismo cultural é hoje um turismo de massas e as centenas de milhar de visitantes que chegam ao Museu Monográfico de 
Conimbriga e à sua paisagem, a paisagem do Oppidum de Conimbriga e das Terras de Sicó, onde se instalou o Circuito da Romanização_ligando Conimbriga à Mãe d'Água do Aqueduto de Alcabideque, ao Museu e Villa Romana do Rabaçal e ao Complexo Monumental de Santiago da Guarda (Villa Romana_Torre Medieval_Solar dos Caminhos de Santiago), testemunham em primeiro lugar a qualidade do produto e do serviço, fator determinante do sucesso e do retorno.

Fig. 5. Impacte económico do turismo de Conimbriga, média anual do período 1995/2014.

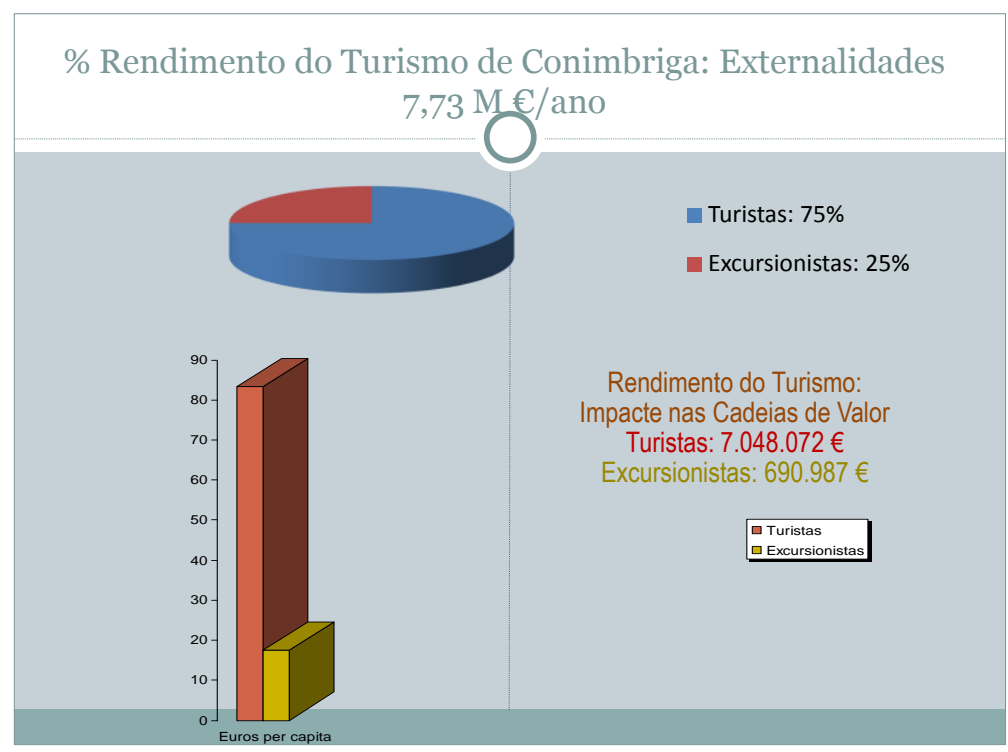

Fonte: Inquérito anual LAC/CEFOP.

Mostram igualmente como o valor acrescentado dos turistas é largamente superior aos dos excursionistas e como, com despesas gerais de funcionamento do museu e ruinas, 
financiadas pelo estado na ordem dos 500 a 600 mil euros/ano, se obtêm, nas Cadeias de Valor do Turismo, retornos superiores a 7 milhões de euros/ano.

\section{Externalidades da economia do Património e do Turismo Cultural}

Mas aqueles exemplos notáveis, que devem ser estudados como fonte de aprendizagem dos bons métodos de gestão, não podem servir para criar a dupla ilusão de que todos os museus ou monumentos são suscetíveis de apresentar um resultado orçamental positivo (em França, só outra instituição cultural, além de Versalhes, gera receitas diretas que lhe permitem autofinanciar-se) ou que o seu impacto económico se reduz à contabilidade das receitas próprias: o efeito multiplicador do seu funcionamento é muito superior a estas receitas e materializa-se sobretudo nas suas externalidades, potenciando todas as Cadeias de Valor da atividade turística e a sua economia a montante e jusante.

O que constitui recurso turístico essencial é a paisagem cultural (ou selvagem, onde a influência antrópica é menos evidente), paisagem humanizada, onde se inscrevem museus e monumentos, parques e áreas protegidas, ou simplesmente, os diversos quadros paisagísticos (do mar à montanha), com os recursos do seu "terroir". A sua leitura e interpretação constituem a base da criação do produto turístico e a sua primeira metamorfose de valor. São a "ecologia da paisagem" (o património material) e a sua "metafísica" (o património imaterial), que constituem a essência do recurso turístico, mas só a sua interpretação e leitura lhe confere um novo acréscimo de valor cultural e económico, transformando o recurso em produto/mercadoria. A paisagem (rural e urbana) não é um livro 
aberto, inteligível empiricamente. A sua transformação em produto turístico passa pela sua legibilidade, que lhe confere valor de uso; é uma metamorfose que, no plano da economia gera valor, e é também um processo de literacia cultural, mediado pela construção da linguagem de comunicação turística, questão pouco estudada; em paralelo, outras estruturas orgânicas, de outras categorias tipológicas do turismo, como seja o Turismo em Espaço Rural, o Turismo Gastronómico e Enológico, o Turismo de Mar e Rio... também elas necessitam de processar os recursos em produtos: o resultado deste processo altera a forma e a essência dos conceitos tradicionais de recurso e de produto turístico. Ao leitor interessado em conhecer a estrutura categorial dos diferentes tipos de turismo, conceptualizados segundo as suas distintas estruturas orgânicas e diferentes produtos oferecidos, aconselhamos a leitura do artigo referido em Bibliografia e titulado "Turismo Cultural e Economia do Património".

A principal quota da renda do gerada pelo património (s)é recolhida externamente às suas estruturas orgânicas nas Cadeias de Valor da atividade turística (alojamento, restauração, lojas e merchandising, animação, guionamento, transporte, agenciamento..), mas são os museus, monumentos e parques naturais, que hoje atraem os turistas, constituindo uns as estruturas orgânicas do turismo cultural e outros as estruturas orgânicas do turismo de natureza. A incompreensão deste paradoxo económico é a causa do conflito histórico entre turismo e desenvolvimento, traduzido no falso dilema "economia ou cultura", mas contém igualmente a chave da sua superação. 


\section{$O$ conceito de externalidade, $a=f(p)$}

Este conceito de "externalidade", na relação entre o património e as Cadeias de Valor da economia do turismo, pode ser transformado num teorema e numa fórmula matemáticas:

Durante longos anos os hotéis e afins corporizaram os principais polos de atração turística. O que mudou deste então?

Seja "a" a variável do alojamento e "p" a variável que representa o conjunto do património natural e cultural. A lei matemática assenta na correspondência entre a e $p$, correspondência unívoca no sentido $a \rightarrow p$. Anteriormente, dizíamos que a variável $p$ é uma função variável de a e escrevemos simbolicamente $p=f(a)$, sendo que a (alojamento) era a variável independente e $\mathrm{p}$ (património) a variável dependente. Ora, o que resulta do emergir de uma nova classe média culta, da emancipação da mulher contemporânea pelo trabalho, de uma juventude cada vez mais instruída e da antecipação da reforma ativa em segmentos da classe média, é uma mudança de gosto e de motivação nas viagens, provocando uma inversão funcional. Atualmente $\mathbf{a}=\mathbf{f}(\mathbf{p})$, isto é, a generalidade das unidades hoteleiras, na sua uniformidade construtiva e de serviços, deixou de ser o polo de atração, tendendo a tornar-se dependente da existência na sua área funcional de mercado de valores patrimoniais conservados e acessíveis ao público. Esta nova relação unívoca tornou o alojamento uma variável económica dependente do património. No campo da matemática, em rigor, a um valor de " $p$ " corresponde um só valor de "a" e, no mercado turístico, o mesmo monumento, sítio ou paisagem é visitável a partir da existência de várias unidades hoteleiras, relativamente próximas. E, ao alterar a relação funcional, põe em causa a própria natureza do alojamento tradicional, pelo menos em quatro dimensões: 
1a: A exigência de qualidade construtiva no que concerne ao valor arquitetónico da obra, correta inserção paisagística e gestão ambiental.

2a A necessidade de conformar os seus serviços com os valores patrimoniais da paisagem cultural onde se insere, oferecendo os seus produtos mais genuínos na construção, restauração e no merchandising.

3a A diversificação da oferta, complementando o serviço de alojamento, restauração e merchandising, com o de animação, e em especial com a proposta de Rotas e Circuitos de Turismo Cultural e de Natureza.

4a A eliminação das barreiras arquitetónicas, de modo a acolher todos os hóspedes com necessidades especiais e a criação de estruturas paramédicas e de lazer adequadas, sobretudo aos turistas seniores: desde o acesso rápido a serviços de saúde aos parques gerontológicos.

\section{Mercado de concorrência ou mercado cooperativo?}

Os novos produtos do turismo cultural e de natureza, como mercadorias que são, possuindo embora um valor acrescentado e de troca comparável às mercadorias comuns, comportam-se face à concorrência de um modo peculiar, que importa pôr em evidência. Cada novo turista ganho para o "gosto" (aqui considerado como categoria) por um determinado produto do turismo cultural ou de natureza, tenderá a procurar e consumir todos os produtos afins, isto é, visitar todos os outros museus, monumentos, parques naturais, etc... Esta concorrência, pela diferenciação, gera complementaridade e redes de cooperação, em vez de exclusão do concorrente.

Assim, os pequenos municípios que concorrem entre si pela primazia dos fluxos turísticos e que não têm escala de 
competição e as entidades regionais de turismo assentes na promoção baseada na diferenciação administrativa municipal, podem ganhar essa escala de competição através da constituição de "unidades territoriais de turismo ambiental" (turismo de cultural e de natureza), organizadas como Circuitos ( intermunicipais e transmunicipais) integradores de todo o património, oferecido sob a forma de grandes Rotas que integram os diversos Circuitos, com itinerários e percursos que atravessam sucessivas vezes o seu concelho, atraindo os turistas pelos valores do património material e imaterial e transformando excursionistas em turistas.

A esta luz também as noções de competitividade ganham aqui um significado próprio e o desenvolvimento económico das novas formas de turismo cria uma dinâmica singular e aglutinadora que determina a evolução de outras áreas económicas a montante e a jusante, como seja, a necessidade de promover uma economia de conservação da natureza e dos patrimónios culturais, e, em paralelo, a promoção da agricultura sustentável e da reforma da construção civil em favor da reabilitação arquitetónica e dos conjuntos urbanos ou a disseminação das infotecnologias e da cultura cibernética.

Podemos agora sistematizar a questão ultrapassando a falácia económica: A visão dominante na atualidade, que soma os proveitos obtidos com as entradas nos museus e afins, com os resultados da sua loja, restaurante, do guionamento e outros serviços proporcionados pelas estruturas do turismo cultural ou do turismo de natureza, constitui uma perspetiva redutora que não tem em conta as externalidades positivas e a mudança de carácter da relação funcional entre as Cadeias de Valor da 
atividade turística e o Turismo Cultural e de Natureza, que designamos genericamente como Turismo Ambiental.

Acresce que às receitas diretas e induzidas do turismo ambiental ( turismo cultural + turismo de natureza) se deve somar, no âmbito da economia, as receitas fiscais, que devolvem ao estado, à administração central e local, o financiamento e investimento realizados.

\section{Ascensão do Turismo Cultural em Portugal. 4 fatores}

A partir de inquéritos e estudos nacionais aos visitantes dos Museus e monumentos (definição do ICOM), bem como de informação recolhida da experiência de Conimbriga/Liga de Amigos de Conimbriga, concluiu-se que este elemento do mercado (Museus e Monumentos), que estrutura o Turismo Cultural, atingiu em Portugal entre 1998 e 2002 um número de visitantes equiparado aos melhores níveis internacionais, e,como adiante se detalha e se analisa, foram revelados os quatro fatores desse progresso:

- O aumento da oferta desencadeou vagas sucessivas de visitantes.

- Desenvolveu-se em Portugal um amplo processo de democratização e qualificação das estruturas museológicas.

_ Os professores e as escolas, em paralelo com as autarquias, trouxeram aos museus novos públicos, o escolar e o das classes populares. Neste contexto, classificam-se os professores como os principais "agentes informais do turismo". As associações de Amigos dos Museus desempenharam também um papel positivo neste processo.

_ As crianças e jovens transformaram-se, eles próprios, em promotores das visitas aos museus. 
A publicação, no espaço de quatro anos, de dois trabalhos sobre a evolução nacional dos públicos dos museus e afins, em paralelo com os estudos de público e mercado realizados a partir de Conimbriga, põe em causa a visão do "senso comum" instalada não apenas na generalidade dos cidadãos mas também a nível dos decisores políticos e económicos. Portugal emerge, já em 1998, como dispondo de valores de procura deste segmento de mercado, que estrutura o Turismo Cultural, ao nível europeu e internacional:

E sublinhamos que estamos a utilizar a definição internacional de museu adotada pelo ICOM, que inclui os monumentos e jardins botânicos, assim como todo o tipo de parque temáticos e museus, conceito que na sua aplicação prática engloba, por exemplo, o Jardim Zoológico e a Aldeia de João Franco, o Portugal dos Pequenitos, mas não os monumentos (Jerónimos, etc, que, como veremos adiante farão ampliar largamente estes valores)...Acresce que os números expressos não incluem os visitantes dos Parques e Reservas Naturais, geridas pelo atualmente designado ICNF_ Instituo de Conservação da Natureza e das Florestas.

1998 8.541.060 Número de visitantes dos museus e afins, em Portugal...mas, $69,6 \%$ na Região de Lisboa, $11,7 \%$ no Norte, 5,8\% no Centro, 3,8\%no Alentejo, 1,4\% no Algarve, 0,8\% nos Açores e $6,9 \%$ na Madeira. (Fonte: Inquérito aos Museus de Portugal, IPM, 2000)

\subsection{9 .609}

Número de visitantes dos museus e afins, em Portugal...53,1\% na Região de Lisboa, $19,9 \%$ no Norte, $11,6 \%$ no Centro, 3,9\% no 
Alentejo, 5,5\% no Algarve, 1,0\% nos Açores e 5,0\% na Madeira. (Fonte: O Panorama Museológico em Portugal 2000-2003. IPM, 2005.)

Se o ano de 1998 representa uma relação de procura elevada, ela concentra-se, no entanto, na região da Grande Lisboa, sendo relevante o número de visitantes na Madeira, a confirmar as potencialidades do seu turismo cultural. Mas já em 2002, fica registada uma efetiva disseminação da procura pelo todo nacional.

Para esta profunda mudança, contribuíram, na nossa opinião, quatro fatores fundamentais que analisaremos de seguida, a partir de um primeiro quadro.

Fig.6. Principais segmentos de público: Monumentos. Jardins Zoológicos, Botânicos e Aquários.

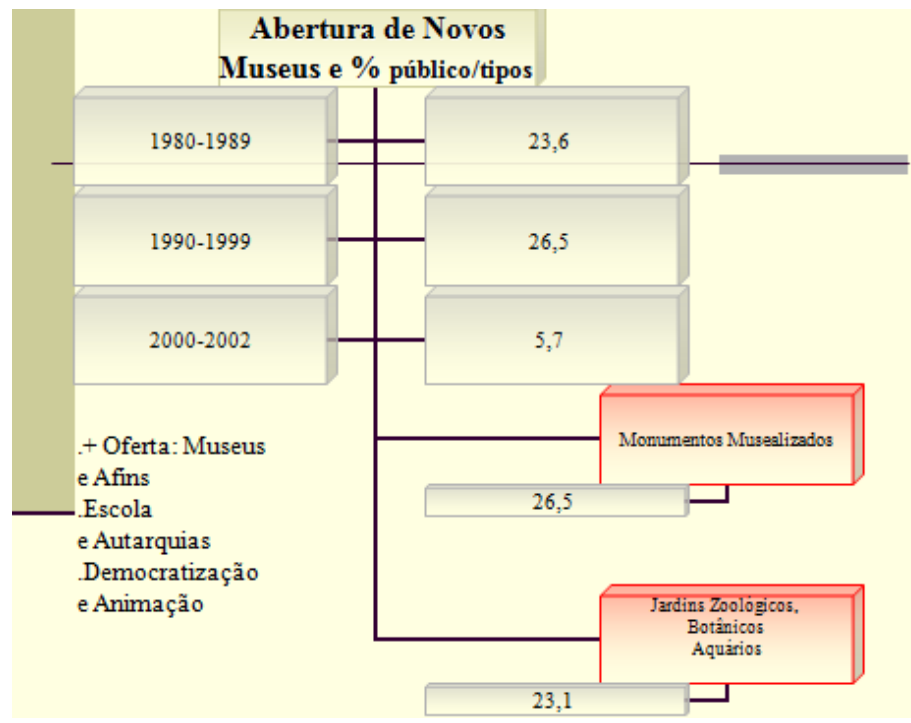

Fonte: O Panorama Museológico em Portugal. 
Em primeiro lugar, verifica-se que o aumento da oferta desencadeou vagas sucessivas de visitantes. Nos vinte anos decorridos entre 1980 e 1999, cresceu em 50,1 \% ( + 57 unidades) o número de museus abertos. Sendo que o segmento dos Jardins Zoológicos, Botânicos e Aquários, representam, só por si, 23,1\% do público e os Monumentos Musealizados 26,5\%. Na década seguinte, o crescimento continuaria com mais uma centena de museus e um acréscimo superior a $35 \%$.

Assim e seguindo um sábio preceito da economia clássica, " a produção da mercadoria, cria a necessidade de a consumir" (Marx), mesmo que o marketing nos queira convencer que é o gosto do público que determina a produção, sendo dialética esta relação, atrevo-me a afirmar que predomina a vontade da produção sobre a necessidade do consumo.

Em segundo lugar, desenvolveu-se em Portugal um amplo processo de democratização e qualificação das estruturas museológicas. Ao contrário da ideia comum de que os nossos museus e monumentos fecham ao fim de semana, a verdade é que, na sua maioria, e na totalidade dos que eram geridos pelo recém-extinto Instituto de Museus e Conservação _IMC, eles abrem anualmente seis dias por semana e apenas à 2a $\underline{a}$ feira fecham, como em todo o mundo, para manutenção. Nesta matéria, a nota negativa vai para a maior parte dos museus das Universidades, que, por força de contingências orçamentais, estão fechados ao domingo e a positiva para o Museu Monográfico de Conimbriga.

Em Conimbriga desenvolve-se uma experiência singular, com a abertura das ruínas e museu 7 dias por semana. Os grupos escolares e os professores que os enquadram têm em regra entrada gratuita, e ao domingo de manhã, uma vez mais os 
museus do ex-Instituto de Museus e Conservação_IMC dão o exemplo de democratização com o acesso gratuito. Generalizouse igualmente o desconto nas entradas para os mais velhos e grupos especialmente carenciados (lares de 3a idade, centros de reabilitação).

O funcionamento regular e democrático dos museus e monumentos, servidos pelas novas TICs_Tecnologias de Informação e Comunicação, constitui o eixo fundamental da animação turística, complementadas com as outras atividades integradas na sua programação_exposições temporárias, teatro, música, etc.

Em terceiro lugar, os professores e as escolas, em paralelo com as autarquias, trouxeram aos museus novos públicos, o escolar e o das classes populares. Trata-se de visitas de estudo, melhor ou pior organizadas, e excursões apoiadas pelos transportes municipais. Não obstante, seria completamente errado interpretar o crescimento do número de visitantes como reportando-se sobretudo aos grupos escolares. Dois dados chegam para o demonstrar: O estudo de 2002 indica que esse valor é de 19\%; o gráfico de visitantes de Conimbriga, nos últimos 10 anos, aponta para uma média variável de $20 \%$ a um terço.

De qualquer modo, o trabalho de campo e a experiência que recolhemos em Conimbriga e na cooperação com outros museus e afins, nomeadamente, o Museu Nacional de História Natural da Universidade de Lisboa_MNHN e o Visonarium, Centro de Ciência promovido pela AEP permite-nos concluir que hoje os professores são os principais agentes informais do turismo. Foi decisivo o seu contributo, em Conimbriga, para o crescimento 
regular do número de visitantes, entre 1991 e 1999, atingindo então o seu ponto mais alto, com 216.517.

Os estudos realizados pelo Museu/IMC//LAC assinalam em 1999 $52.560(24,4 \%)$ estudantes nacionais e 858 (0,5\%), estudantes estrangeiros. $E$, num ciclo de quatro anos do Visionarium, já na década seguinte, o número de visitantes escolares ultrapassou os 150.000 .

Já no MNHN a primeira exposição científica sobre os Dinossáurios, ainda em 1993, atingiria um número recorde superior a 300.000 !

Em quarto lugar, as crianças e jovens transformaram-se, eles próprios, em promotores das visitas aos museus. Trata-se de um fenómeno recorrente, por exemplo, mos museus e centros de ciência e, em particular, nas exposições científicas. Da colaboração entre a Liga de Amigos de Conimbriga e o seu Centro de Formação de Professores e Profissional CEFOP.Conimbriga, com o MNHN, nas exposições de Dinossáurios Robot de 1993 e 2002, foi notório que os jovens escolares e dos jardins-de-infância que as visitavam durante a semana, enquadrados pelos professores e educadores das suas instituições, regressavam ao fim de semana acompanhados por todas as gerações familiares, pais, avós, tios, ou irmãos, e o seu peso económico é de tal ordem que, na Loja que continha o merchandising das exposições referidas, as receitas se elevavam 5 ou 6 vezes no período de sábado a domingo, e subiam a mais de $30.000 € /$ mês. Esta análise é igualmente válida para as áreas protegidas, embora aqui a dinâmica de visitas encontre nas associações ambientalistas o primeiro grande impulso. Infelizmente a maior parte dos Centros de Interpretação dos 
nossos parques e reservas naturais estão fechados ao fim de semana.

De acordo com o inquérito realizado pelo INE em 2011, os 397 Museus, jardins zoológicos, botânicos e aquários registaram um total de 13,5 milhões de visitantes e detinham um acervo de 21,7 milhões de bens em 2011. Do acervo total, 38,2\% pertencia aos Museus de Ciências e de Técnica. Os mais visitados foram os Jardins zoológicos, botânicos e aquários, com $24,6 \%$ do total de visitantes.

Em 2011 as galerias de arte e outros espaços de exposições temporárias (887 espaços) promoveram 7304 exposições e apresentaram 297836 obras de 53951 autores. O número de visitantes foi de 8,8 milhões, significando em média, 1210 visitantes por exposição realizada. O INE não nos diz qual a natureza deste público, no domínio do turismo e do excursionismo, e não sabemos quantas destas galerias estão integradas em espaços musealizados, mas é óbvio que não podemos resumi-lo aos residentes locais.

Podemos agregar ainda a panorâmica dos Espetáculos ao Vivo e aos Recintos de espetáculos, sem podermos estabelecer a sua conexão com a atividade turística: No conjunto dos espetáculos ao vivo, em 2011 realizaram-se 25871 sessões, com um total de 8,5 milhões de espetadores/as e uma receita de 55,7 milhões de euros. O teatro liderou o número de sessões ( $47 \%$ do total), mas foram os concertos de música rock/pop que tiveram maior número de espetadores/as (1,5 milhões) e geraram mais receitas (23,7 milhões de euros).

De acordo com informação do Orçamento Geral do Estado, a despesa consolidada do Ministério da Cultura em 2011 ascendeu a 215,5 milhões de euros, significando um decréscimo de $8,8 \%$ 
em relação a 2010 ( um valor equivalente ao do orçamento de um único grandes estabelecimento museológico de Paris, ou melhor, um Centro de Ciência e das Indústrias, La Villete).

Segundo os dados recolhidos através do Inquérito ao Financiamento Público das Atividades Culturais, em 2011 as Câmaras Municipais afetaram um financiamento de 406,8 milhões de euros às atividades culturais, fundamentalmente para os seguintes domínios: património cultural $(19,7 \%)$, publicações e literatura $(15,4 \%)$, atividades socioculturais $(14,7 \%)$, recintos culturais (12,3\%) e música $(7,7 \%)$.

A descentralização do acesso aos museus pode ser documentado pela sua localização regional: Norte 108, Centro 98, Lisboa 80, Alentejo 53, Algarve 20, Região Autónoma dos Açores 20, Região Autónoma da Madeira 18.

\section{Agregação dos visitantes e espetadores das estruturas orgânicas do turismo cultural}

Museus, jardins zoológicos, botânicos e aquários_13,5 milhões

Galerias de arte e outros espaços de exposições temporárias_ 8,8 milhões

Espetáculos ao Vivo e aos Recintos de espetáculos_8,5 milhões Faltam-nos ainda os monumentos e sítios. 
Fig. 7. Tipologia dos museus.

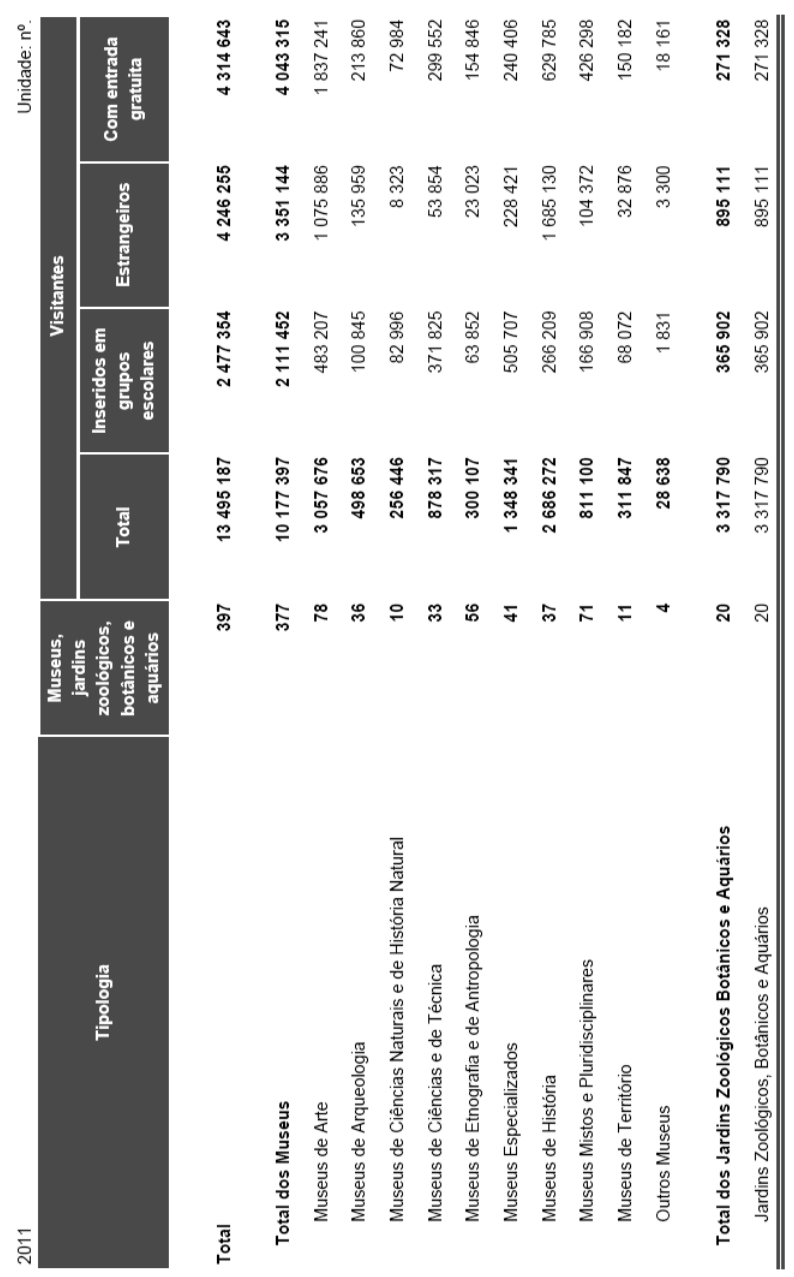

Fonte: Instituto Nacional de Estatística. 
O pessoal a tempo completo era de 4.470 pessoas e a tempo parcial 692.

Fig. 8. Quadro de visitantes dos museus.

\begin{tabular}{|c|c|c|c|c|c|}
\hline \multirow[b]{2}{*}{ Âmbito geográfico } & \multirow{2}{*}{$\begin{array}{l}\text { Museus, jardins } \\
\text { zoológicos. } \\
\text { botánicos e } \\
\text { aquários }\end{array}$} & \multicolumn{4}{|c|}{ Visitantes } \\
\hline & & Total & $\begin{array}{c}\text { Inseridos em grupos } \\
\text { escolares }\end{array}$ & Estrangeiros & $\begin{array}{l}\text { Com entrada } \\
\text { gratuita }\end{array}$ \\
\hline Portugal & 397 & 13495187 & 2477354 & 4246255 & 4314643 \\
\hline Continente & 359 & 12610560 & 2428072 & 4113187 & 4194336 \\
\hline Norte & 108 & 3476013 & 1088048 & 691928 & 1233778 \\
\hline Centro & 98 & 1181083 & 268567 & 127184 & 591033 \\
\hline Lisboa & 80 & 6898965 & 945360 & 2969786 & 2095570 \\
\hline Alentejo & 53 & 392096 & 73548 & 47949 & 195655 \\
\hline Algarve & 20 & 662403 & 52549 & 276340 & 78300 \\
\hline Regiäo Autónoma dos Açores & 20 & 125464 & 17328 & 30482 & 46383 \\
\hline Regiäo Autonoma da Madeira & 18 & 759163 & 31954 & 102586 & 73924 \\
\hline
\end{tabular}

Fonte: Instituto Nacional de Estatística.

O mito de que os visitantes dos nossos museus são sobretudo estrangeiros e jovens escolares, cai aqui. Os grupos escolares representam cerca de $20 \%$ e os estrangeiros um pouco mais de $30 \%$. Analisemos então a distribuição geográfica dos visitantes dos museus uma década depois dos inquéritos que referimos anteriormente, deixando entre parênteses os dados anteriores:

\section{1-13495 187}

Número de visitantes dos museus e estabelecimentos afins em Portugal...50,9\% (53,1\%) na Região de Lisboa; 25,8\% (19,9\%) no Norte; $8,8 \%$ (11,6\%) no Centro; $2,9 \%$ (3,9\%) no Alentejo; 4,9\% no Algarve (1,0\%); 0,9 (1\%) nos Açores e 5,6 (5,0\% ) na Madeira.

$\mathrm{O}$ desenho de uma estrutura descentralizada, com maior incidência em Lisboa, consolida-se, com a subida do Norte e um crescimento importante no Algarve, mas que partiu de um nível 
muito reduzido. O Centro retrocede claramente, em termos de peso relativo e também o Alentejo. A importância turística do Algarve e a sua elevada sazonalidade justifica o desenvolvimento destas estruturas do turismo cultural, mas também da possibilidade e necessidade de levar a cabo um plano de reestruturação das suas estruturas de apoio ao turismo, complementando os produtos de sol e praia e lazer, com os novos produtos do turismo cultural e de natureza, sob pena de se tornar menos atrativo para a classe média-média e média-alta e tender para receber sobretudo os turistas da classe médiabaixa e das classes populares, que pesam no rendimento dos principais destinos turísticos internacionais apenas 7\%, mesmo que consiga captar alguns segmentos da classe alta, os quais, apenas representam na generalidade dos destinos turísticos pouco mais de $5 \%$. Veja-se o caso do destino turístico Espanha, quando ocupava o 2 o lugar no ranking mundial.

Fig. 9. O peso esmagador da classe média no destino turístico. Espanha.

\begin{tabular}{lrrrr} 
NIVEL DE RENTA & \\
\hline Total turistas & 57.414 & 55.762 & $100 \%$ & $-2,9 \%$ \\
Alta & 2.465 & 2.903 & $5,2 \%$ & $17,8 \%$ \\
Media / Alta & 13.864 & 12.654 & $22,7 \%$ & $-8,7 \%$ \\
Media & 37.273 & 36.326 & $65,1 \%$ & $-2,5 \%$ \\
Media / Baja & 3.087 & 2.889 & $5,2 \%$ & $-6,4 \%$ \\
Baja & 726 & 990 & $1,8 \%$ & $36,5 \%$ \\
\hline
\end{tabular}

Fonte: Instituto de Estudios Turísticos, 2007-2008.

Analisemos agora as outras estruturas orgânicas do Turismo Cultural, Monumentos, Conjuntos histórico-monumentais e 
Sítios: Tomemos o resumo estatístico da evolução verificada no número de visitantes dos museus e monumentos nacionais tutelados agora pela Direção Geral do Património Cultural_ DGPC, que extinguiu e integrou muitas das instituições ligadas ao património que atrás mencionámos, um total de 16 museus e 8 palácios, Conventos, Mosteiros e outros monumentos:

Em 2012, 3.175.585 visitantes, com destaque para Museu Nacional dos Coches_184.105; o Museu Nacional de Arte Antiga_ 119.951; o Mosteiro dos Jerónimos_ 694.156; A Torre de Belém_520.061; o Mosteiro da Batalha_ 271.912: o Palácio Nacional de Mafra_235.670.

Em 2013_ 3.440 .818 visitantes, com destaque para Museu Nacional dos Coches_ 189.015; o Museu Nacional de Arte Antiga_138.166; o Mosteiro dos Jerónimos_ 722.758; A Torre de Belém_ 537.855; o Mosteiro da Batalha_ 291.455: o Palácio Nacional de Mafra_244.489 .

Em 2013_ 3.577 .433 visitantes, com destaque para Museu Nacional dos Coches_ 206.887; o Museu Nacional de Arte Antiga_221.675; o Mosteiro dos Jerónimos_807.845; A Torre de Belém_ 530.903; o Mosteiro da Batalha_ 300.565: o Palácio Nacional de Mafra_274.255.

É óbvio que carecemos de um estudo autónomo do número de visitantes dos monumentos nacionais. Tomemos alguns valores parcelares: Na cidade do Porto, o Palácio da Bolsa incorpora 288.705 visitas guiadas. Outro grupo de monumentos classificados pela UNESCO, no centro de Portugal, Universidade de Coimbra - Alta e Sofia, regista 355.000 visitantes de 60 países diferentes. Na mesma cidade de Coimbra, o Portugal dos Pequenitos assinala 228.000 visitantes em 2014. As principais estruturas orgânicas de um dos segmentos do turismo cultural, o 
turismo religioso, são os santuários; os serviços religiosos para peregrinos no Santuário de Fátima representam 3.209.000 participantes em 2014.Juntemos estes valores aos do quadro seguinte:

Fig.10 . Visitantes dos Monumentos nacionais

$\begin{array}{lr}\text { Palácio Nacional da Ajuda } & 53.534 \\ \text { Palácio Nacional de Mafra } & 274.255 \\ \text { Panteão Nacional } & 89.629 \\ \text { Total } & 417.418 \\ \text { World Heritage List of UNESCO } & \\ \text { Convento de Cristo } \quad \text { Convent of Christ in Tomar } & 209.294 \\ \text { Mosteiro de Alcobaça } \quad \text { Monastery of Alcobaça } & 187.499 \\ \text { Mosteiro da Batalha } \quad \text { Monastery of Batalha } & 300.565 \\ \text { Mosteiro dos Jerónimos } & \text { Monastery of the Hieronymites } \\ \text { Torre de Belém } \quad \text { Tower of Belém } & 807.845 \\ \text { Total } & 530.903 \\ & \end{array}$

Fonte: DGPC, 2014

Ficamos com um valor de cerca de 8,5 milhões de visitantes portadores de bilhete. Podemos estimar, à escala nacional, tendo como base os quadros seguintes, que revelam a existência no nosso país de 3.859 monumentos, conjuntos históricomonumentais e sítios, um número global acima de 12 milhões de visitantes,

O que ressalta deste quadro é a sua disseminação por todo o país: Lisboa já não é a capital macrocéfala da cultura nacional. As estruturas orgânicas do Turismo Cultural possuem os recursos potenciais para generalizar no nosso país toda a gama de produtos do turismo cultural. Paradoxalmente, o Algarve surge no fim da lista, com apenas 121. 
Fig.11. Distribuição nacional de Monumentos, Conjuntos históricomonumentais e sítios.

\begin{tabular}{|c|c|c|c|c|}
\hline \multirow{2}{*}{\multicolumn{5}{|c|}{ Gategoria dos bens imóveis }} \\
\hline & & & & \\
\hline Ambito Geograffico & Total & Monumentos & Conjuntos & Sitios \\
\hline Portugal & 3869 & 2946 & 475 & 439 \\
\hline Continente & 3407 & 2500 & 468 & 439 \\
\hline Norte & 1183 & 882 & 141 & 160 \\
\hline Minho-Lima & 181 & 134 & 22 & 25 \\
\hline Cávado & $\mathbf{9 9}$ & 80 & 16 & 23 \\
\hline Ave & 97 & 68 & 15 & 14 \\
\hline Grande Porto & 176 & 130 & 37 & 9 \\
\hline Tamega & 147 & 105 & 13 & 29 \\
\hline Entre Douro e Vouga & 31 & 21 & 3 & 7 \\
\hline Douro & 291 & 248 & 24 & 19 \\
\hline Alto Trás-os-Montes & 161 & 116 & 11 & 34 \\
\hline Centro & 9900 & 778 & 124 & 88 \\
\hline Baixō Vougaa & 57 & 36 & 15 & 6 \\
\hline Baixo Mondego & 136 & 111 & 21 & 4 \\
\hline Pinhal Litoral & 43 & 34 & 6 & 3 \\
\hline Pinhal Interior-Norte & 89 & 72 & 10 & 7 \\
\hline Dăó-Lafỏes & 161 & 115 & 17 & 29 \\
\hline Pinhal Interior-Sul & 17 & 13 & 0 & 4 \\
\hline Serra da Estréla & 30 & 23 & 1 & 6 \\
\hline Beira Interior-Norte & 113 & 91 & 14 & 8 \\
\hline Beira Interior-Sul & 41 & 33 & 5 & 3 \\
\hline Gova da Beira & 34 & 25 & 6 & 3 \\
\hline Oeste & 136 & 113 & 14 & 9 \\
\hline Mêdiō Tejó & 133 & 112 & 15 & 6 \\
\hline Lisboa & 545 & 390 & 119 & 36 \\
\hline Grande Lisboa & 442 & 313 & 101 & 28 \\
\hline Peninsula de Setúbal & 103 & 77 & 18 & 8 \\
\hline Alentojo & 568 & 362 & 69 & 137 \\
\hline Alentejo Litoral & 35 & 23 & 3 & 9 \\
\hline Alto Alentejo & 158 & 86 & 13 & 59 \\
\hline Alentejo Central & 202 & 122 & 32 & 48 \\
\hline Baixo Alentejo & 96 & 71 & 10 & 15 \\
\hline Lezíria do Tejo & 77 & 60 & 11 & 6 \\
\hline Algarve & 121 & 88 & 15 & 18 \\
\hline Regiăo Autónomá dos Açores & 286 & 286 & 0 & 0 \\
\hline Regiăo Autónoma da Madeira & 166 & 159 & 7 & 0 \\
\hline
\end{tabular}

Fonte: Instituto Nacional de Estatística

Estão classificados como Monumentos Nacionais 786, como Imóveis de Interesse Público 2.360 e como Imóveis de Interesse Municipal 713. Constituem propriedade pública 1.299 desses bens, propriedade privada 571, mista 52, faltando determinar a posse de 1.937. 
Também o quadro das galerias e exposições de arte, tal como dos seus visitantes, mostra a sua efetiva regionalização por todo o país, sendo notória, pela negativa, a sua escassa presença no destino turístico Algarve.

Fig.12. Distribuição geográfica das exposições

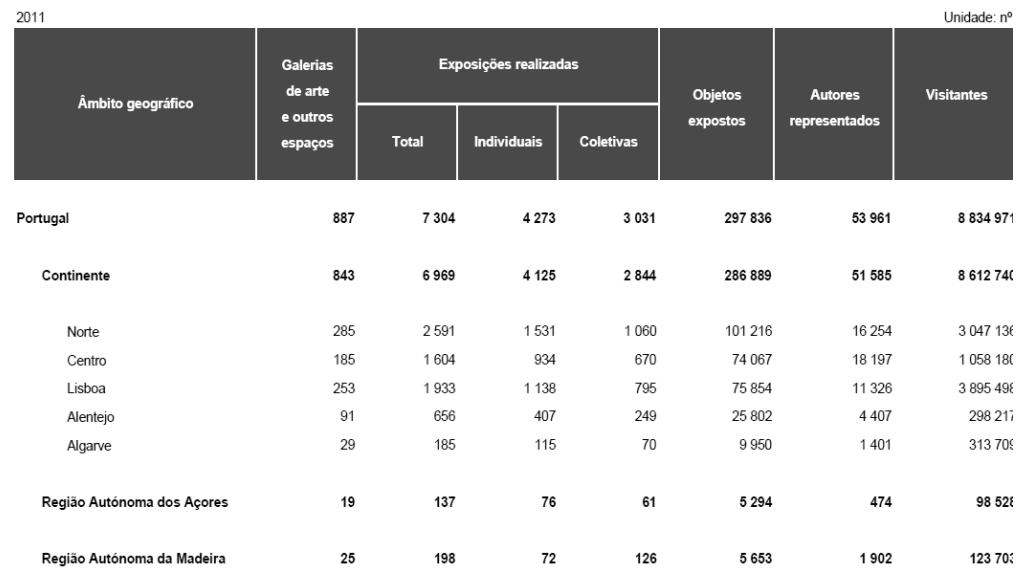

. Fonte: Instituo Nacional de Estatística.

Concentrando agora a análise apenas nos museus e monumentos ( 28 museus e 5 palácios) tutelados pelo ex-IMC no período 2007 - 2010, a partir do estudo denominando de "Estatísticas de Públicos de Museus", foi possível extrair as seguintes conclusões: _ O visitante é maioritariamente nacional (57\%), embora o público estrangeiro tenha um peso muito significativo (42\%).

_ Nos museus, acentua-se a predominância de público nacional (66\%) sobre o público estrangeiro (33\%), enquanto nos palácios se registou o contrário: preponderância do público estrangeiro (52\%) em relação ao nacional (47\%). 
Ora, como o turismo internacional contribui diretamente para o setor exportador e para a melhoria balança de pagamentos, é significativa tal percentagem, quando a relacionamos com o número total dos seus visitantes: 2.368 .562 em 2010 e 2.490 .241 em 2011, distribuídos conforme o quadro anexo:

Fig.13. Visitantes dos museus e palácios tutelados pelo ex-IMC.

\begin{tabular}{|c|c|c|c|c|c|c|c|c|c|c|c|c|c|}
\hline Evolução Mensal 2011 & Janeiro & Fevereiro & Março & Abril & Maio & Junho & Julho & Agosto & Setembra & Outubro & Novenbor & Dezembry & TOTAL \\
\hline C.-M. Dr. Anastácio Gonçalves & 673 & 777 & 964 & 626 & 1.551 & 592 & 833 & 415 & 56 & 716 & 817 & 681 & 9.214 \\
\hline M do Abade de Baçal & 825 & 1.113 & 923 & 1.594 & 2725 & 2.113 & 2.931 & 2.231 & 892 & 1.304 & 1.513 & 1.039 & 19.203 \\
\hline M. de A Aberto Sampaio & 1.449 & 2.599 & 4.888 & 4.898 & 7.268 & 7.260 & 6.732 & 4.992 & 28.725 & 2.106 & 2.122 & 1.542 & 74.590 \\
\hline M de Arte Popular & 1.420 & 1.046 & 1.061 & 1.345 & 945 & 719 & 2.544 & 959 & 758 & 1.141 & 720 & 3.162 & 15.820 \\
\hline M. de Aveiro & 2.230 & 2.398 & 1.870 & 3.030 & 10.349 & 3.905 & 3.164 & 3.895 & 4.451 & 5.373 & 2.202 & 2215 & 45.082 \\
\hline M. dos Biscainhos & 1.568 & 1.831 & 3.768 & 3.774 & 3.507 & 2.608 & 3.602 & 4.020 & 2.375 & 2.175 & 2.073 & 948 & 32.249 \\
\hline M. de Cerámica & 575 & 805 & 929 & 1.228 & 1.139 & 1.273 & 1.629 & 1.136 & 666 & 991 & 480 & 415 & 11.266 \\
\hline M do Chiado & 4.550 & 4.141 & 4.898 & 2850 & 4.053 & 3.282 & 5.149 & 7.115 & 4.213 & 3.317 & 2.823 & 1.906 & 48.297 \\
\hline M. Et e Avq Dr. Joaquim Manso & 265 & 331 & 472 & 421 & 2532 & 789 & 1.115 & 1.443 & 1.966 & 880 & 358 & 244 & 10.816 \\
\hline M. de Evora & 1.788 & 2.381 & 2.764 & 2720 & 2740 & 2.206 & 2.287 & 3.240 & 2.357 & 2.536 & 1.336 & 1.339 & 27.694 \\
\hline M de Franósco Tavares Pr. Jr. & 1.064 & 1.421 & 2079 & 1.262 & 1.377 & 1.629 & 1.665 & 1.014 & 645 & 814 & 799 & 772 & 14.541 \\
\hline M. Grão Vasco & 2.625 & 3.437 & 5.186 & 4.242 & 7.021 & 7.204 & 8.247 & 19.714 & 9.846 & 4.586 & 5.313 & 4.155 & 81.576 \\
\hline M. da Guarda & 214 & 152 & 292 & 452 & 598 & 373 & 451 & 1.640 & 392 & 567 & 803 & 1.032 & 6.966 \\
\hline M. de José Malhoa & 1.157 & 1.185 & 1.740 & 1.940 & 2196 & 1.381 & 1.699 & 1.640 & 901 & 1.425 & 1.457 & 1.287 & 18008 \\
\hline M. de Lamego & 611 & 1.024 & 1.195 & 1.522 & 2789 & 1.946 & 2.882 & 2.422 & 3.449 & 2.011 & 817 & 735 & 21.403 \\
\hline M. Monográ́fico de Conímbriga & 2.961 & 5.430 & 9.390 & 10.146 & 9.890 & 12.826 & 10.326 & 13.580 & 8.728 & 7.172 & 3.954 & 3.461 & 97.865 \\
\hline M. da Música & 649 & 553 & 1.470 & 996 & 1.447 & 1.217 & 800 & 293 & 394 & 736 & 850 & 776 & 10.241 \\
\hline M. Nac de Arqueologia & 6.454 & 6.220 & 6.025 & 6.980 & 6.452 & 5.397 & 7.564 & $16.41 \mathrm{~d}$ & 5.492 & 7.455 & 5.799 & 5.089 & 85.343 \\
\hline M. Nac de Arte Antiga & 9.497 & 12.700 & 9.754 & 11.108 & 13.940 & 7.899 & 11.263 & 14.241 & 15.498 & 8.892 & 7.724 & 6.520 & 129.036 \\
\hline M. Nac do Azulejo & 4.057 & 4.988 & 6.274 & 9.300 & 9.531 & 8.458 & 7.925 & 8.566 & 10.187 & 8.378 & 5.200 & 4.043 & 86.907 \\
\hline M. Nac dos Coches & 8.069 & 10.276 & 13.785 & 18.691 & 23246 & 17.325 & $18.47 \mathrm{~g}$ & 23.700 & 21.677 & 19.307 & 9.448 & 7.018 & 191.021 \\
\hline Núdeo de Vila Viçosa & 846 & 973 & 1.401 & 1.236 & 1.145 & 906 & 665 & 1.400 & 955 & 890 & 712 & 419 & 11.548 \\
\hline M. Nac de Etnologia & 732 & 800 & 1.680 & 730 & 1.207 & 387 & 1.145 & 361 & 537 & 558 & 664 & 398 & 9.199 \\
\hline M. Nac de Machado de Castro & 1.356 & 2.036 & 4.469 & 6.748 & 8.633 & 7.023 & 3.856 & 6.133 & 2.927 & 2.296 & 1.845 & 666 & 47.988 \\
\hline M. Nac de Soares dos Reis & 3.496 & 3.564 & 5.728 & 5.002 & 6.334 & 4.402 & 4.102 & 3.783 & 3.431 & 3.220 & 3.654 & 3.339 & 50.057 \\
\hline M. Nac do Teatro & 3.247 & 3.799 & 3.845 & 3.650 & 3.899 & 3.950 & 2.672 & 2.739 & 2.760 & 2.790 & 3.290 & 2.534 & 39.175 \\
\hline M. Nac do Traje & 3.370 & 3.515 & 3.730 & 4.501 & 5.197 & 4.905 & 5.506 & 2.511 & 3.534 & 4.809 & 3.196 & 2.733 & 47.507 \\
\hline MD.D. de Sousa & 4.819 & 4.653 & 5.029 & 4.750 & 5.874 & 5.846 & 6.559 & 1.753 & 3.256 & 5.215 & 4.288 & 4.669 & 56.711 \\
\hline M. de Terras de Miranda & 154 & 697 & 905 & 1.171 & 1.833 & 2.658 & 1.689 & 2.384 & 1.687 & 1.756 & 332 & 382 & $15.64 \mathrm{C}$ \\
\hline P. Nac da Ajuda & 2.117 & 119 & 4.262 & 4.690 & 4.670 & 2.185 & 3.665 & 4.170 & 4.574 & 5.504 & 3.928 & 2.525 & 42.409 \\
\hline P. Nac de Queluz & 9.272 & 8.125 & 12.776 & 15.284 & 18.504 & 16.916 & 12.405 & 13.423 & 18.152 & 14.586 & 7.582 & 5.968 & 152.993 \\
\hline P. Nac de Sintra & 11.302 & 14.869 & 23.246 & 36.413 & 47.560 & 37.957 & 37.564 & 45.940 & 49.428 & 39.805 & 15.409 & 14.308 & 373.801 \\
\hline P. Nac. de Mafra & 20.562 & 18.426 & 22608 & 22844 & 24.420 & 20.708 & 22.821 & 34.519 & 24.917 & 20.167 & 15.048 & 14.028 & 261.068 \\
\hline Paço dos Duques & 13.622 & 15.866 & 21.189 & 33.761 & 34.342 & 37.738 & 38.686 & 59.095 & 33.756 & 25.233 & 14.875 & 16.836 & 344.999 \\
\hline \begin{tabular}{|r|} 
TOTAL \\
\end{tabular} & 127.598 & 142.250 & 190.595 & 229.905 & 278.914 & 235.992 & 242.682 & 310.883 & 274.096 & 208.711 & 131.431 & 117.124 & 2.490 .241 \\
\hline & & & & & & & & & & & & 197 & \\
\hline TOTAL & 127.598 & 2.250 & 190.595 & 29.905 & 78.914 & 235.992 & 242.682 & 310.883 & 274.096 & 208.711 & 131.431 & 117.184 & 2.490 .2 \\
\hline
\end{tabular}

Fonte: Direção Geral do Património Cultural.

Agregação dos visitantes e espetadores das estruturas orgânicas do turismo cultural

Museus, jardins zoológicos, botânicos e aquários_13,5 milhões

Galerias de arte e outros espaços de exposições temporárias_ 8,8 milhões

Espetáculos ao Vivo e aos Recintos de espetáculos_8,5 milhões 
Monumentos, conjuntos histórico-monumentais e sítios_ 12 milhões

Falta contabilizar o número de visitantes das áreas protegidas, para avaliarmos a dimensão da procura do turismo de natureza. O ICNF regista apenas o número de visitas guiadas 28.896, em 2015. Só no Parque Natural da Serra da Estrela, segundo fonte da GNR, contam-se por ano mais de 3 milhões de visitantes, a maior parte excursionistas de um só dia. O Parque Nacional da Peneda Gerês não terá um número inferior. Mas não existem estatísticas fiáveis, apenas alguns estudos parcelares, relacionando património e turismo e o seu impacte económico.

Um exercício de comparação com o número de espetadores dos estádios de futebol, permite perceber como existe uma falsa perceção acerca do peso social e económico dos espetáculos desportivos face aos espetáculos e outras manifestações associadas ao turismo cultural. É que o número oficial de espetadores dos clubes de futebol, divulgados pela sua Liga, não ultrapassa os 3 milhões, face aos mais de 42,8 milhões envolvidos em atividades culturais. Sendo certo que a diversidade dos expetadores de futebol é seguramente muito menor do que a dos visitantes dos museus, e, provavelmente, estamos a falar de um núcleo de algumas dezenas ou escassas centenas de milhar que se repetem nos estádios domingo a domingo. O quadro anexo dá-nos apenas uma pálida imagem dessa realidade, comparando os espetadores dos principais estádios de futebol com os visitantes dos monumentos referidos. 
Fig. 14. Top 5 dos espetadores dos estádios de futebol e visitantes dos monumentos..

\begin{tabular}{|c|c|c|c|c|}
\hline 10 & $722.506 *$ & Benfica & $\begin{array}{l}\text { Mosteiro dos } \\
\text { Jerónimos }\end{array}$ & $644.729 * *$ \\
\hline 20 & 570.766 & Porto & Torre de Belém & 530.903 \\
\hline 30 & 558.649 & Sporting & $\begin{array}{l}\text { Palácio Nacional } \\
\text { de Sintra }\end{array}$ & 360.756 \\
\hline 40 & 235.634 & Braga & $\begin{array}{l}\text { Mosteiro da } \\
\text { Batalha }\end{array}$ & 336.249 \\
\hline 50 & 189.105 & V.Guimarães & Paço dos Duques & 287.499 \\
\hline 60 & 92.189 & G.Vicente & $\begin{array}{l}\text { Palácio Nacional } \\
\text { de Mafra }\end{array}$ & 262.291 \\
\hline
\end{tabular}

Fonte: Federação Portuguesa de Futebol. IGESPAR

*Dados de 2010/2011 ** Dados de 2010 Sendo os da Torre de Belém de 2014

Não obstante, o Turismo Desportivo e de Desporto deve ser reconhecido como uma das categorias tipológicas do turismo contemporâneo com relevância económica e social, mas a sua projeção, muito restrita aos níveis superiores do futebol, surge desmesurada e irreal no nosso país, e, provavelmente, insustentável no atual modelo de negócios: entre os organizadores do Euro 2008, a única entidade que exibiu lucros significativos foi a empresa multinacional denominada FIFA, que toma forma jurídica de uma associação sem fins lucrativos! Esta questão tem relevância para o investimento estratégico do país e põe em causa as suas prioridades políticas: basta lembrar os 10 estádios construídos para o Euro 2008, que deixaram para trás 
além de um investimento improdutivo do governo de muitas centenas de milhões de euros, dívidas de outros milhões das autarquias e défices acumulados de gestão desses estádios aos clubes e às suas SAD e de novo às autarquias, na ordem dos milhões/ano. E levanta ainda o problema da veracidade e tratamento desigual da comunicação social destas duas facetas da nossa vida social, já que a divulgação e o marketing em geral constituem poderosos estímulos à procura social.

\section{CONCLUSÕES}

Analisámos primeiro como na economia do turismo se processa a geração do valor e a produção de mais-valias nas suas Cadeias de Valor. Para chegarmos mais tarde ao conceito das suas externalidades, que é fundamental para a compreensão do carácter específico da economia do turismo, da sua produtividade e competitividade.

Concluímos que o que constitui recurso turístico essencial é a paisagem cultural ( ou selvagem, onde a influência antrópica é menos evidente), humanizada, com os seus museus, monumentos, áreas protegidas e quadros paisagísticos, que contêm outros recursos no seu "terroir". A transformação da paisagem em produto turístico passa pela sua legibilidade, que Ihe confere valor de uso: é uma metamorfose que, no plano da economia gera valor, e é também um processo de literacia cultural, mediado pela construção da linguagem de comunicação turístico; em paralelo, outras estruturas orgânicas, de outras categorias tipológicas do turismo, também elas necessitam de processar os recursos em produtos: o resultado deste processo altera a forma e a essência dos conceitos tradicionais de recurso e de produto turístico. 
Durante longos anos os hotéis e afins corporizaram os principais polos de atração turística. Ora, o que resulta do emergir de uma nova classe média culta, da emancipação da mulher contemporânea pelo trabalho, de uma juventude cada vez mais instruída e da antecipação da reforma ativa em segmentos da classe média, é uma mudança de gosto e de motivação nas viagens, provocando uma inversão funcional. Atualmente $a=f(p)$, isto é, a generalidade das unidades hoteleiras, na sua uniformidade construtiva e de serviços, deixou de ser o polo de atração, tendendo a tornar-se dependente da existência na sua área funcional de mercado de valores patrimoniais conservados e acessíveis ao público. Esta nova relação unívoca tornou o alojamento uma variável económica dependente do património.

O capital turístico não se constitui apenas com o investimento imobiliário e em equipamentos de turismo (capital fixos), e em capital variável ( quadros e trabalhadores especializados, planeamento, gestão e marketing), mas cada vez mais com a adição de investimento intelectual, científico, cultural, na criação de produtos turísticos, como são hoje os do turismo cultural e os de turismo da natureza ( também denominado ecoturismo).

Estes novos produtos turísticos, como mercadorias que são, possuindo embora um valor acrescentado e de troca comparável às mercadorias comuns, comportam-se face à concorrência de um modo peculiar. Esta concorrência, pela diferenciação, gera complementaridade e redes de cooperação, em vez de exclusão do concorrente. E o desenvolvimento económico das novas formas de turismo cria uma dinâmica singular e aglutinadora que determina a evolução de outras áreas económicas a montante e a jusante, como seja, a necessidade de promover uma economia de conservação da natureza e do património cultural. 
A autonomia financeira e de gestão dos museus, monumentos e parques, acompanhada pelo apoio e investimento do estado na retribuição dos serviços educativos e culturais prestados, a sua orientação estratégica para conquistar os públicos jovens, democratizar o acesso e projetar o marketing do turismo ambiental ( turismo cultural + turismo de natureza) no mercado global, constituem uma das chaves múltiplas do sucesso destas entidades orgânicas do turismo cultural e de do turismo de natureza, e da sua eficiência turística, mas também do desenvolvimento da atividade turística como placa giratória da criação de riqueza e da promoção de mais emprego e novos perfis profissionais.

\section{BIBLIOGRAFIA}

Abramsky, D. J., Dawe, S., Thurley, S., Clare, R., Jardine, I., Johnson, S., (2010). Investing in success. Heritage and UK tourism economy. The Heritage Lottery Fund (HLF): London, UK

Carvalho, J. M. C. R. L. (2009). Conservação do Património. Políticas de susten-tabilidade económica (orientação do Professor Catedrático José Lamas). Tese de Doutoramento. Lisboa: IST.

Costa, J. S. (coordenador científico do estudo); Brito, P. Q., Carvalho, A., Carvalho, P. S., Patrício, O. (Diretora Geral), (2013). Impacto Económico da Fundação de Serralves. Relatório Final. Promotor, Fundação de Serralves. Coordenação Geral do Projeto, Business School. Porto.

Instituto de Estudios Turisticos, Encuesta de Gastos Turísticos (EGATUR), www.iet.tourspain.es (acesso em 3 dezembro de 2011) 
Informação Estatística, www.ine.pt (acesso em 3 dezembro de 2011)

Instituto Nacional de Estatística. Portugal

https://www.ine.pt/xportal/xmain?xpid=INE\&xpgid=ine base da dos (acesso em 3 dezembro de 2011)

Neves, J., Fradique, N. (2010). Estatísticas de Públicos de Museus e o Panorama museológico em Portugal. Estatísticas de Públicos de Museus. 2007 - 2010. 2o Encontro do IMC no Palácio Nacional de Queluz. IMC/OC.

Queirós, A. (2009). Series de Investigación Iberoamericana en Museología. Año 1, Volumen 1. Os Museus e o Novo Paradigma do Turismo. Departamento de Ciências e Técnicas do Património da Faculdade de Letras da Fundação Universidade do Porto. Edição digital, 311/314

Queirós, A. (2013). A new alliance, environnemental tourisme and cultural landscape. In Landscape and Imagination, Towards a new baseline for education in a changing world. Paysage et Invention. Evolution des enseignements dans un monde en transition. UNISCAPE, 2013. Bandecchi\&Vivaldi, Florence, 107112.

Queirós, A. (2013). Critical Contribution to XXI Century Tourism Satellite Account and the Iberian market evolution .In J. M. M. Jiménez (Coordinador) La Economía en la Sociedad del (des)Conocimiento (pp. 263-264 e 1021 a 1041). Coordinador José Maria Moreno Jiménez. Asociación Internacional de Economía Aplicada. ASEPELT. Universidad Zaragoça.

Queirós, A. (2014). Turismo Cultural e Economia do Património. In Journal of Tourism and Development, no 21/22, Volume 4, INVTUR. University of Aveiro, 107-117. 
Queirós, A. (2014). Inquérito anual LAC/CEFOP. Impacte económico do turismo de Conimbriga, 1995/2014. Liga de Amigos de Conimbriga: Conimbriga.

Santos, M. (coord.), Neves, J. e outros (2000). Inquérito aos Museus em Portugal, MC/IPM. Lisboa.

Santos, M., Oleiro B. e outros (2005). O Panorama Museológico em Portugal [2000-2003]. Equipa do OAC: Maria de Lourdes Lima dos Santos (coordenação). Equipa do IPM/RPM Manuel Bairrão Oleiro (coordenação)

UNWTO. Statistics \& Economic Measurement of Tourism [http://www.world-tourism.org/] (acesso em 3 dezembro de 2011) 